\title{
TỪ LÝ THUYẾT KIẾN TẠO ĐẾN LÝ THUYẾT KIẾN TẠO XÃ HộI
}

\author{
Nguyễn Quang Thuấn* \\ Trung tâm Ngôn ngũ và Quốc tế học, Truờng Đại học Ngoại ngũu, ĐHQGHN, \\ Phạm Văn Đồng, Cầu Giáy, Hà Nội, Việt Nam \\ Nhận bài ngày 30 tháng 06 năm 2017 \\ Chỉnh sửa ngày 14 tháng 07 năm 2017; Chấp nhận đăng ngày 28 tháng 07 năm 2017
}

Tóm tắt: Lý thuyết kiến tạo và lý thuyết kiến tạo xã hội là hai lý thuyết quan trọng có quan hệ khăng khít với nhau cho phép giải thích quá trình phát triển nhận thức của con người. Lý thuyết kiến tạo khẳng định rằng kiến thức được kiến tạo thông qua hoạt động và tư duy về hoạt động. Cũng giống như lý thuyết kiến tạo, lý thuyết kiến tạo xã hội cũng coi kiến thức là sản phẩm của một quá trình kiến tạo, nhưng sự kiến tạo này mang tính xã hội mà không mang tính cá nhân. Trong khuôn khổ bài viết này, chúng tôi cố gắng phân tích và làm rõ thêm các luận điểm quan trọng của hai lý thuyết này, đặc biệt việc vận dụng chúng vào dạy và học ngôn ngữ.

Từ khóa: Lý thuyết kiến tạo, lý thuyết kiến tạo xã hội, đồng hóa, điều chỉnh

\section{1. Đặt vấn đề}

Lý thuyết kiến tạo và lý thuyết kiến tạo xã hội nghiên cứu quá trình phát triển nhận thức của con người. Hai lý thuyết này đã cho phép giải thích quá trình thụ đắc và lĩnh hội tri thức mới. Hai lý thuyết này đã và đang được ứng dụng trong nhiều ngành khoa học khác nhau, đặc biệt là trong giáo dục trong đó có giáo dục ngoại ngữ. Ở nhiều nước trên thế giới, hai lý thuyết này được chọn làm cơ sở khoa học cho đổi mới giáo dục. Tuy nhiên, không phải ai cũng hiểu và đặc biệt vận dụng hiệu quả các lý thuyết này vào dạy và học nói chung và dạy và học ngoại ngữ nói riêng. Trong những dòng dưới đây, chúng tôi sẽ trình bày, phân tích và làm sáng tỏ thêm những luận điểm cơ bản của hai lý thuyết học quan trọng này, đặc biệt nhấn mạnh vai trò của chúng trong giáo dục nói chung và giáo dục ngoại ngữ nói riêng.

\section{Lý thuyết kiến tạo}

Lý thuyết kiến tạo (constructivisme) được hình thành chủ yếu dựa trên các công trình nghiên cứu của hai nhà khoa học, những

\footnotetext{
*ĐT.: 84-912004484

Email: ngquangthuan@yahoo.fr
}

người mà vào đầu thế kỷ $\mathrm{XX}$ đã nghiên cứu về sự phát triển của hệ thống tư duy ở trẻ em và thanh thiếu niên. Đó là Piaget, nhà tâm lý học người Thụy sĩ và Bruner, nhà tâm lý học người Mỹ. Các công trình nghiên cứu của hai ông đã mang đến cho chúng ta một quan điểm, một cách nhìn mới về về học và kiến thức. Lý thuyết kiến tạo ra đời nhằm phản ứng lại các lý thuyết bẩm sinh và lý thuyết hành vi. Lý thuyết kiến tạo quan tâm đồng thời đến quá trình học và khoa học luận. Thật vậy, các khái niệm của lý thuyết kiến tạo thường khớp nối với nhau phản ứng lại mô hình học hành vi. Cần phải nhắc lại rằng, lý thuyết hành vi quan tâm nghiên cứu những thay đổi ở cấp độ hành vi hiển nhiên. Theo thuyết hành vi, dạy được coi như đổ đầy một cái bình, con người sinh ra, còn trắng, chưa biết gì về thế giới được đặc trưng bởi những cố gắng của người học nhằm tích lũy các kiến thức cũng như cố gắng của người dạy nhằm truyền đạt các kiến thức ấy. Đó là một đường hướng truyền đạt, thụ động, chủ yếu được định hướng và kiểm soát bởi người dạy. Giống như nhận thức luận khách quan (épistémologie objectiviste), thuyết hành vi ủng hộ sự tồn tại của một kiến thức về thế 
giới. Mục đích của người học là lĩnh hội kiến thức đó và mục đích của người dạy là truyền đạt kiến thức đó. Vậy thì học là đồng hóa thực tế khách quan này.

Trái lại, lý thuyết kiến tạo cho rằng mỗi một người học kiến tạo thực tế khách quan đó hoặc ít ra là hiểu dựa trên nhận thức và các trải nghiệm của mình. Thật vậy, lý thuyết kiến tạo khẳng định rằng một cá nhân phát triển nhận thức thông qua kiến tạo hay xây dựng kiến thức của mình trong hành động và trong tình huống và bằng suy nghĩ về hành động và kết quả của hành động. Con người nắm bắt và hiểu được các tình huống mới qua cái mà mình đã biết và thay đổi kiến thức có trước của mình để thích nghi với các tình huống ấy. Mỗi một thích nghi cho phép mở rộng và làm giàu thêm vốn kiến thức của một cá nhân, sự tiến triển này tiếp tục cho phép người đó làm chủ được các tình huống càng ngày càng phức tạp.

Các lý thuyết kiến tạo trước hết muốn chứng minh sự phát triển ngôn ngữ không phải được thực hiện bằng việc tích luỹ các mẩu, cục, một sự chồng đống các thu nhận kiến thức liền kề nhau, mà là bởi một sự xuất hiện các hệ thống liên tiếp gắn kết cái này với cái kia, mỗi một hệ thống đó tạo thành các loại kỹ năng đặc thù.

Thật vậy, các công trình khoa học của Piaget $(1975,1977)$ về sự phát triển các hoạt động trí tuệ đã cho phép làm sáng tỏ quá trình học, thụ đắc kiến thức của người học.

Theo lý thuyết kiến tạo, lĩnh hội một ngôn ngữ sử dụng các cấu trúc (structures) nhận thức, các cấu trúc này được xây dựng bởi chính chủ thể trong quá trình hoạt động và bởi chính hoạt động đó. Đó là quá trình cá nhân tổ chức các hoạt động tìm tòi, khám phá thế giới bên ngoài và cấu tạo lại chúng dưới dạng các sơ đồ (schèmes hay schémas) hay cấu trúc nhận thức. Các sơ đồ nhận thức này được hình thành từ các hành động bên ngoài và được nhập tâm. Sự phát triển nhận thức là sự phát triển hệ thống các sơ đồ hay cấu trúc nhận thức. Các sơ đồ này có bản chất thao tác được và được trẻ em kiến tạo lên bằng chính các hoạt động của mình. Chính vì vậy, trẻ em, để lĩnh hội một ngôn ngữ, phải có một số tối thiểu các cấu trúc nhận thức, phải đối diện trực tiếp với các hiện tượng ngôn ngữ mà nó sẽ hành động nhờ vào và cho các hiện tượng ngôn ngữ này. Hoạt động này chủ yếu là thực hành và diễn ra với khả năng của trẻ. Các khả năng này thay đổi theo từng thời gian phát triển của trẻ. Hoạt động này sẽ dẫn đến hình thành các trạng thái cân bằng chuyển giao để làm chủ ngôn ngữ.

Lý thuyết kiến tạo cũng chỉ ra rằng nguời học ngoại ngữ phải qua các giai đoạn (étapes) và các bậc (stades) mà đặc tính của nó không nằm trong sự vắng mặt của các qui luật tiếp nhận và sản sinh, mà trong sự xuất hiện liên tục các qui luật tiếp nhận và sản sinh khác nhau mà dựa trên các qui luật này các kỹ năng giao tiếp được hình thành ở người lớn bản ngũ hoạt động.

Trước các dữ liệu ngôn ngữ, người học có thể bị rơi vào một tình huống xung đột giữa các cấu trúc kiến thức đã được kiến tạo hay tích hợp (các cấu trúc được thu đắc và lĩnh hội) với các các dữ liệu ngôn ngữ mới, người học có thể đồng hóa (assimilation) hoặc phải điều chỉnh (accommodation) nhờ vào các kiến thức, các kỹ năng, các kinh nghiệm... mà người học có vào thời điểm đó.

Theo lý thuyết kiến tạo, học chính là áp dụng các kiến thức có trước. Học làm một cái gì đó, chính là làm cái gì đó chủ động. Đó chính là kích hoạt và áp dụng kiến thức có trước. Học những điều gì mới phải luôn luôn được thực hiện bằng cách đi từ cái mà người học đã biết, ở vào thời điểm hành động. Người ta làm cho các tình huống có nghĩa không phải bằng cách xử lý các thông tin mà bằng cách kích hoạt ngay lập tức các kiến thức có trước của mình. Không có sự kích hoạt này, tình 
huống mà người ta đang ở trong đó và cái mà người ta hiểu như sự kiện, sự việc, vv. đều không có nghĩa gì đối với một người. Bởi vì không có kích hoạt kiến thức có trước thì cũng không có xử lý thông tin. Vì vậy, học trước

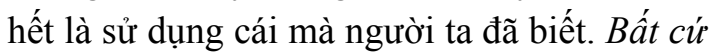
một việc học nào cũng được thưc hiện tù các kiến thức có truớc. Đó là nguyên lý kiến tạo thứ nhất.

Khi học diễn đạt nói, tôi phải huy động và sử dụng các kiến thức như ngữ âm, từ vựng, ngữ pháp, văn hóa, các qui tắc ngôn ngữ xã hội... đã thụ đắc và lĩnh hội được để giới thiệu, thuyết phục, từ chối hay chấp nhận một vấn đề gì đó, vv. Tuy nhiên, tôi đã nhận ra rằng mình chưa giao tiếp hiệu quả hay thành công như mong muốn, ví dụ như chưa thuyết phục được đồng nghiệp chấp nhận hay làm một cái gì đó. Thế thì tôi phải thay đổi cách giao tiếp bằng cách sử dụng các từ ngữ, các chiến lược giao tiếp sao cho có thể thuyết phục được đồng nghiệp của mình. Như vậy, việc học nào cũng phải dựa trên sụ biến đổi các kiến thức có trước. Đây là nguyên lý kiến tạo thứ hai.

Hai nguyên lý học vừa nêu tương ứng với hai chức năng nhận thức được xác nhận bởi Piaget $(1975,1977)$ : đồng hóa và điều chinh. Một sự tương tự dựa trên cơ quan tiêu hóa của con người đã cho phép giải thích hai chức năng nhận thức mà Piaget đã mượn của bộ môn sinh học. Nói một cách khác, theo quan điểm kiến tạo, hệ thống nhận thức của một người hoạt động giống như hệ thống tiêu hóa của con người. Học, đó là đồng hóa và điều chỉnh. Đồng hóa và điều chỉnh cũng là hai chức năng nhận thức, chúng cho phép hiểu kiến thức hoạt động như thế nào để tiếp cận cái chura biết tù̀ cái đã biết.

Đồng hóa là làm cho một cái gì đó tương tự một cái khác. Đồng hóa các kiến thức mới, đó là làm cho các kiến thức mới này tương tự như các kiến thức mà người ta có sẵn trong bộ não. Đồng hóa có nghĩa là biến đổi các kiến thức mới này thành các kiến thức cũ. Nói một cách khác, chủ thể biến đổi các kiến thức mới này để tích hợp chúng vào các kiến thức có trước của anh ta. Đồng hóa, đó là biến đổi cái mới và lĩnh hội nó trong cách thể hiện của riêng mình. Điều này giải thích vì sao người ta yêu cầu người học không nhắc lại nguyên văn mà phải hiểu trong các từ ngữ của riêng mình. Bằng cách đồng hóa nguyên văn, người ta sẽ không học được gì mới bởi vì người ta không biến đổi cái gì. Thuyết hành vi không quan tâm đến đồng hóa mà chỉ quan tâm điều chỉnh giản lược thành một sự thay đổi thụ động hành vi. Hành động đồng hóa chỉ có thể dẫn đến cái mới nếu có hoặc chỉ có điều chỉnh, có nghĩa là biến đổi các kiến thức cũ.

Điều chỉnh là việc biến đổi các kiến thức cũ hay có trước thành kiến thức mới hoặc làm mới kiến thức cũ. Khi mà các kiến thức mới kháng cự không cho phép quá trình đồng hóa diễn ra, cơ chế điều chỉnh can thiệp kéo theo sự thay đổi các kiến thức cũ của cá nhân sao cho tích hợp các kiến thức mới với kiến thức có trước. Trong trường hợp này, người học bị biến đổi bởi môi trường. Kiến thức luôn luôn đổi mới hay thay đổi ở mỗi lần bị kích hoạt. Để tích hợp một kiến thức mới, cần phải kết hợp đồng hóa và điều chỉnh: kiến thức có trước đồng hóa kiến thức mới bằng cách điều chỉnh. Trong bất cứ tình huống nào, những thay đổi như vậy sẽ xẩy ra và trong phần lớn thời gian sẽ gây ra các điều chỉnh ít nhiều quan trọng.

Khái niệm "ngôn ngữ trung gian" (interlangue) do một số nhà lý luận và phương pháp dạy học pháp như là Py hay Selinker (1972) phát triển trùng hợp với lý thuyết Piaget. Lỗi mà người học tiếng nước ngoài mắc phải không thể được giải thích bằng việc các liên kết yếu đi và cũng không phải là do các hiện tượng chuyển giao và giao thoa lạm dụng giữa tiếng mẹ đẻ và tiếng nước ngoài, mà đúng hơn là do các hoạt động siêu sản sinh (opérations de surgénéralisation) của hệ thống ngôn ngữ trung gian gồm các bình diện 
khác nhau như là ngữ âm, hình vị-cú pháp, ngữ nghĩa, vv.).

Hai hoạt động cơ sở của hoạt động học cho phép hình thành hệ thống ngôn ngữ trung gian của người học là đồng hoá (assimilation) và điều chỉnh (accommodation).

Đồng hoá là hoạt động của cấu trúc hành động nhận thức và bằng hoạt động này, người học tích hợp các dữ liệu thu nhận từ thế giới bên ngoài (các dữ liệu nghe, nhìn của ngôn ngữ cập nhật trong thực tiễn) vào các cấu trúc kiến thức mà anh ta có trước. Nếu như các dữ liệu này "kháng cự lại” không cho phép quá trình đồng hoá diễn ra, tích hợp có thể kéo theo thay đổi các cấu trúc có sẵn : quá trình điều chỉnh sẽ diễn ra. Theo Piaget (1975), đồng hóa và điều chỉnh hình thành một cặp đôi không thể thiếu được cho hoạt động nhận thức mà các quá trình thăng bằng khác nhau của nó sẽ được phát triển trong sự thăng bằng của các cấu trúc nhận thức.

Cần phải nhắc lại rằng các phương pháp dạy học ngoại ngữ theo đường hướng giao tiếp (approche communicative) về nguyên tắc gần với lý thuyết kiến tạo. Phương tiện, thiết bị được sản xuất ra theo lý thuyết kiến tạo dựa đồng thời trên sự mô tả phỏng theo cách tiếp cận khái niệm-chức năng và trên nguyên tắc là hoạt động quan trọng nhất của người học phải được dưa trên các điều kiện học thích hợp như triển khai các tình huống giao tiếp tạo thuận lợi nhất có thể cho giao tiếp của người học ở trên lớp. Đặc biệt là các đường hướng này đã thành công trong việc chỉ ra các cơ chế tiếp nhận và sản sinh.

\section{Lý thuyết Bruner: "học thông qua khám phá phát hiện"}

Lý thuyết kiến tạo của Bruner (1966) dựa trên giả thuyết là cá nhân kiến tạo nghĩa một cách cá nhân thông qua học. Sau này ông có thêm yếu tố xã hội vào lý thuyết của mình (Bruner, 1986). Vậy thì quá trình học cũng chính là quá trình kiến tạo nghĩa. Lý thuyết kiến tạo của Bruner dựa trên hai nguyên lý:

- Kiến thức được người học kiến tạo một cách chủ động mà không phải được tiếp nhận một cách bị động từ môi trường.

- Học là một quá trình thích nghi dựa trên kinh nghiệm mà người ta có về thế giới và kinh nghiệm này không ngừng được bổ xung và phát triển.

- Chính vì vậy, kiến tạo kiến thức là một quá trình năng động mà trong quá trình này người học sử dụng các kiến thức có trước của mình giống như một giàn giáo và trên giàn giáo này các kiến thức mới lấy làm nền tảng và các biểu đạt mới về thế giới sẽ phát triển. Hơn thế nữa, có tính đến các kinh nghiệm mới và tiếp xúc với môi trường, các biểu đạt hay hình ảnh tri nhận nhận này sẽ trở nên phức tạp không ngừng thay đổi. Nói một cách khác, cái mà một cá nhân sẽ học được tùy thuộc vào cái mà mình đã biết: một cá nhân càng biết nhiều thì càng có thể học được nhiều.

Bruner quan tâm đặc biệt tới các giai đoạn phát triển nhận thức của trẻ em. Theo ông có 3 giai đoạn phát triển nhận thức ở trẻ em: giai đoạn thu động hoạc không hoạt động, giai đoạn hình và giai đoạn ký hiệu.

\section{1) Giai đoạn thụ động hoặc không hoạt động (tù khi sinh đến khoảng 3 tuổi)}

Trong giai đoạn đầu này, trẻ em nhận thức về môi trường chỉ qua các hành động mà chúng thực hiện. Các vật được miêu tả và giải thích theo các từ ngữ mà đứa trẻ sử dụng khi thực hiện các hành động. Trẻ em không thể nói một chiếc xe đạp hoạt động như thế nào nhưng nó có thể chỉ ra chúng làm gì với chiếc xe. Đối với những đứa trẻ mà tuổi ở giai đoạn này, giá trị của học nằm ở trình độ "chỉ ra" và "bắt chước" hơn là "nói".

2) Giai đoạn hình ảnh (khoảng tù 3 tuổi đến 8 tuổi) 
Trong giai đoạn thứ hai này, trẻ em có thể nhớ lại và sử dụng thông tin qua hình ảnh (hình ảnh tri nhận và hình). Trí nhớ qua nhìn tăng và chúng có thể hình dung hay nghĩ tới các hành động mà không cần kiểm nghiệm ngay lập tức. Các quyết định còn dựa trên các nhận thức hơn là ngôn ngữ.

\section{3) Giai đoạn ký hiệu (khoảng 8 tuổi)}

Trong giai đoạn thứ hai này, trẻ em bắt đầu sử dụng các ký hiệu (từ hay hay tranh ảnh) để biểu đạt về người, các hoạt động và các sự việc. Chúng có thể nghĩ và nói về các sự vật bằng các thuật ngữ trừu tượng. Chúng cũng có thể hiểu được một số "khái niệm đã được xác định", ví dụ như chúng có thể tranh luận về khái niệm "đồ chơi". Chúng cũng có thể hiểu tốt hơn một số nguyên tắc toán học và sử dụng các ngôn ngữ diễn đạt tượng hình, ví dụ, "hãy đù̀ng khóc về những cái mà mày không thể”.

- Bruner cũng đưa ra 6 chỉ dẫn làm bộc lộ sự phát triển nhận thức của trẻ em:

- Trả lời các kích thích bằng cách khác nhau hơn là bao giờ cũng một cách.

- Tập hợp các sự kiện dưới "hình thức lưu giữ” đáp ứng môi trường.

- Cải thiện khả năng ngôn ngữ.

- Tác động qua lại một cách hệ thống với người đỡ đầu (cha mẹ, giáo viên, hoặc bất cứ ai có thể làm mẫu).

- Sử dụng ngôn ngữ giống như là công cụ phục vụ tổ chức môi trường.

- Cải thiện khả năng tạo nên với nhiều yêu cầu.

Đối với Bruner, người học chọn và biến đổi thông tin, người học đưa ra các giả thiết và quyết định theo cấu trúc của các hình ảnh tri nhận. Cấu trúc này giúp người học đưa ra nghĩa của các thông tin mới. Cấu trúc các hình ảnh tri nhận, bằng cách nào đó, dùng làm khung khái niệm cho phép giải thích thế giới. Cấu trúc này có thể được trung gian hóa bởi hành lý kinh nghiệm và vốn sống của mỗi người. Mỗi người kiến tạo một hình ảnh duy nhất bằng cách kết hợp các thông tin có sẵn trong bộ não với thông tin mới mà anh ta nhận được. Tuy nhiên, một số nhà lý thuyết khẳng định rằng không phải duy nhất chỉ có các hình ảnh tri nhận sản sinh trong hoàn cảnh học. Người ta cũng đánh giá rằng các kiến thức được kiến tạo một cách xã hội bởi vì mọi người đều có thể tiếp cận các ý tưởng và các thông tin. Ví dụ như mọi người có thể tranh luận về một chủ đề nào đó trên báo, trên truyền hình, vv. sau đó cùng đưa ra các kết luận chung. Do vậy, một nhóm các nhân cùng chia sẻ một câu chuyện, một ngôn ngữ chung, một hoạt động văn hóa hay khoa học nào đó sẽ có một kho tư liệu về các thực hành chung và một tập hợp các kiến thức ít nhiều giống nhau.

Bruner đặc biệt quan tâm tới việc tổ chức dạy học. $\mathrm{Cu}$ thể, các nhà trường phải thừa nhận các giai đoạn phát triển nhận thức và làm việc từ các giai đoạn này. Ý tưởng học

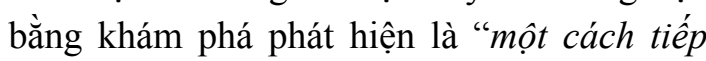
cận dạy học mà ở đó người hoc tác động qua lại với môi truoòng bằng cách khám phá và sủ dụng các vật, tranh luận các câu hỏi và các mâu thuẫn hoặc thực hiện các thủ nghiệm" (Ormrod, 1995: 442). Bruner cho rằng người học có khả năng hiểu và nhớ các khái niệm mà họ khám phá được. Tuy nhiên, các nghiên cứu đã chứng minh rằng kết quả trái ngược nhau của việc học theo phương pháp khám phá phát hiện. Hơn thế nữa, giáo viên cũng lưu ý rằng học theo phương pháp khám phá phát hiện có may mắn thành công hơn, nếu người học có kiến thức tiên quyết và nếu như họ học trong các hoàn cảnh không được cấu trúc.

\section{Lý thuyết của Piaget: đồng hóa và điều chỉnh}

Piaget đặc biệt được biết đến như là một chuyên gia tâm lý học trẻ em vì các công trình nghiên cứu của ông liên quan tới phát triển trí 
tuệ của trẻ em. Lý thuyết Piaget đã có những đóng góp to lớn vào các nghiên cứu phát triển nhận thức. Theo lý thuyết nhận thức Piaget:

- Người học kiến tạo các kiến thức của mình bằng hành động của riêng mình. Kiến thức hay tri thức có thể thu nhận được thông qua các hoạt động và hành động trực tiếp trong tương tác với người khác trong các quan hệ xã hội.

- Phát triển nhận thức là một nội quá trình độc lập ít nhạy cảm với các hiệu ứng bên ngoài, đặc biệt các hiệu ứng của người dạy.

- Sự phát triển này mang tính phổ biến và được thực hiện qua các bước liên tiếp nhau.

- Khi một cá nhân đạt tới một trình độ hoạt động lô-gic có thể lập luận một cách lô-gic dù nội dung kiến thức là gì.

- Người học chỉ có thể "đồng hóa" các kiến thức mới nếu có các cấu trúc nhận thức cho phép.

Thực vậy, các nghiên cứu của ông nhằm vào việc phát triển các năng lực tư duy và năng lực suy luận của con người bắt đầu từ việc quan sát chính các con của ông. Rất nhiều người tin ông, nhưng cũng không ít người người phê phán ông và cho rằng các nguyên lý Piaget phức tạp, quá sâu và đôi khi không hiểu được và nhìn chung quá đơn giản hoá. Tuy nhiên, hai đặc tính quan trọng của lý thuyết Piaget được thừa nhận một cách rộng rãi trong cộng đồng khoa học và hỗ trợ tất cả các lý thuyết khác của ông : các giai đoạn phát triển nhận thức và các quá trình hoạt động nhận thức.

Về phát triển nhận thức, theo Piaget, tất cả trẻ em đều trải qua 4 giai đoạn: 1) giai đoạn cảm giác - vận động, 2) giai đoạn tiền thao tác hay thực hành), 3) giai đoạn thao tác hay thực hành cu thể và 4) giai đoạn thao tác chính thức. Dù rằng các giai đoạn này có thể thay đổi theo lứa tuổi, tất cả trẻ em đều có thể đạt được trình độ năng lực suy luận cao nhất của mình trong một khung cảnh tương tự. Sau đây là các đặc tính của trẻ em tương ứng với các giai đoạn phát triển của chúng:

\section{4) Giai đoạn cảm giác - vận động (tù khi sinh đến khoảng 2 tuổi)}

Trong giai đoạn này, trẻ em khám phá thế giới xung quanh chúng qua cảm giác và các hoạt động vận động của chúng. Ở đầu giai đoạn này, bản thân chúng không thể khác biệt với môi trường của chúng. Nói một cách khác là chúng không thể thấy một cái gì đó không tồn tại. Thật vậy, trong giai đoạn này, trẻ em phát triển trí tuệ thực hành (trước ngôn ngữ) trên cơ sở các phản xạ tự nhiên. Giai đoạn từ khi sinh ra đến khoảng một tuổi rưỡi này dẫn đến các hành vi ngày càng phức tạp nhờ vào việc xây dựng các cấu trúc kiến thức, một loại kiến thức dạng hành động (actes), cho phép đồng hóa thế giới nhưng cũng cho phép điều chỉnh với các đặc tính của chúng.

Suốt trong giai đoạn này, diễn ra các thay đổi cơ bản nhất và nhanh nhất trong phát triển nhận thức của trẻ. Thật vậy, khi mới sinh, trẻ em chỉ có khả năng hoạt động riêng rẽ như là mút tay, mút kẹo, sờ ngẫu nhiên các vật, nghe, nhìn, vv. Hơn thế nữa, tất cả được tập trung quanh cơ thể của nó. Đối với một đứa trẻ còn rất bé, các vật không tồn tại. Với tư cách là chủ thể, nó không có ý thức về bản thân nó. Nhưng trong suốt mười tám tháng đầu, một “cuộc cách mạng cô-péc-níc thật sự” đã diễn ra. Cơ thể của trẻ từ nay không còn là trung tâm của thế giới nữa, mà là một vật trong tất cả các vật khác có quan hệ với nhau hoặc vì mối liên hệ nguyên nhân kết quả, hoặc vì mối quan hệ không gian, toàn bộ trong một không gian kết nối với nhau bao trùm tất cả. Những thay đổi cơ bản này xẩy ra trước sự tiếp thu ngôn ngữ, điều này chứng tỏ rằng kiến thức gắn kết với hoạt động ở mức nào và không chỉ gắn với nói ra thành lời. 
Kiến thức không bắt đầu bằng cái "tôi"” và cũng không bằng vật mà nó bắt đầu bằng các tương tác.

5) Giai đoạn tiền thao tác hay thực hành (khoảng 2 đến 7-8 tuổi)

Trong giai đoạn này, bắt đầu xuất hiện chức năng ký hiệu hay cũng gọi là chức năng biểu tượng. Chức năng này tương ứng với một sự phân biệt giữa "cái biểu đạt" và "cái được biểu đạt” và nội hiện của sự bắt chước. Chính chức năng này cho phép tưởng tượng và tư duy : từ nay, đứa trẻ có thể tưởng tượng một vật vắng mặt, ví dụ nó có thể cầm một cái gậy làm giả một cái ô tô, sau đó một cái xe đạp. Chức năng mới này mở đầu một giai đoạn phát triển nhận thức mới: trí tuệ được phát triển bằng tưởng tượng và bằng tư duy, và không chỉ bằng hành động nữa. Ngôn ngữ hình thành một phần của chức năng ký hiệu. Trẻ em phát triển các kỹ năng giao tiếp cao hơn qua ngôn ngữ và tham gia vào các hoạt động hình tượng như vẽ các vật và chơi trò chơi giả vờ hay tưởng tượng.

Cấu trúc kiến thức không còn là công cụ phổ cập duy nhất bởi vì khái niệm hóa cũng đã có mặt. Xây dựng lại dưới dạng khái niệm tất cả cái đã được thực hiện qua các hoạt động suốt trong giai đoạn cảm giác - vận động.

Bây giờ, với chức năng ký hiệu học, đứa trẻ có thể tưởng tượng các vật không thể nhìn thấy, các hoạt động quá khứ và các hoạt động tương lai. Chúng phát triển các kỹ năng đếm như là gắn một con số cho mỗi một vật thuộc một nhóm các đồ vật nào đó nếu như chúng đếm các vật này.

Trong giai đoạn này, tính tự cho mình là trung tâm cũng xuất hiện. Nó được biểu lộ bằng việc vắng mặt khả năng chuyển hồi và một số nét đặc trưng của tư duy của trẻ em: tính nhân tạo, có nghĩa là mọi vật, mọi hiện tượng tự nhiên đều là nhân tạo - do con người làm ra - trẻ em có xu thế tin là như vậy, tính vật linh, có nghĩa là xu thế coi các điều, các vật đều là đang sống, ví dụ cái đèn đang sống là vì nó chiếu sáng, cái ô tô đang sống vì nó chạy như người... Chúng cải thiện tốt hơn trình độ tự kiểm tra của chúng và có khả năng làm chậm lại sự thoả mãn, nhưng chúng vẫn còn coi mình là trung tâm.

Chúng không có khả năng thực hiện cái mà Piaget gọi là các nhiệm vụ bảo toàn (nhiệm vụ đòi hỏi thừa nhận rằng một chất nào đó vẫn là chính nó mặc dù bề ngoài thay đổi).

6) Giai đoạn thao tác hay thực hành cu thể (khoảng 7-8 đến 11-12 tuổi)

Chúng cải thiện tốt hơn kỹ năng suy luận trừu tượng và kỹ năng khái quát từ những kinh nghiệm cụ thể.

Chúng có thể thực hiện các nhiệm vụ bảo toàn.

7) Giai đoạn của các thao tác hình thíc (tù 11-12 đến 15 tuổi)

Chúng có thể thiết lập và kiểm tra các giả thiết, tổ chức thông tin và suy luận khoa học.

Chúng có thể chứng minh được các kết quả của tư duy trừu tượng dưới hình thức vật chất mang tính ký hiệu, như chữ viết chẳng hạn.

Piaget cho rằng sự phát triển của một đứa trẻ từ giai đoạn này sang giai đoạn khác được thực hiện qua một quá trình tác động qua lại với môi trường của nó và quá trình này là quá trình tăng dần. Trẻ em phát triển khi chúng đối diện với những đặc tính khác mới của môi trường, những đặc tính khác lạ với chúng, có nghĩa là các đặc tính không tương ứng với các quan niệm hàng ngày của chúng về thế giới. Khi đó sẽ xẩy ra một "sự mất thăng bằng" và đứa trẻ tìm cách giải quyết vấn đề mất thăng bằng này qua hai quá trình thích nghi có thể. Hoặc đứa trẻ tích hợp các kiến thức mới vào các kiến thức mà nó có trước - quá trình này gọi là quá trình đồng hoá (processus d'assimilation), hoặc nó phải thay đổi các kiến thức của nó đã có để thu nhận 
kiến thức mới - quá trình này gọi là quá trình điều chỉnh (processus d'accommodation).

Ormrod (1995) tóm tắt các khái niệm cơ bản của Piaget về sự phát triển nhận thức của trẻ em như sau:

- Trẻ em là những người học tích cực và hứng thú.

- Kiến thức của chúng về thế giới được tích hợp tốt hơn và được tổ chức hơn với thời gian.

- Trẻ em học qua hai quá trình đồng hoá và điều chỉnh.

- Sự phát triển nhận thức phụ thuộc vào sự tác động qua lại với môi trường xã hội và thể chất.

- Quá trình cân đối hoá hoặc giải quyết sự mất cân đối giúp trẻ em phát triển các cấp độ phức tạp của tư duy một cách ý nghĩa hơn.

- Sự phát triển nhận thức được thực hiện qua 4 giai đoạn mang tính chất khác nhau.

Các nghiên cứu mới đây đã đặt lại vấn đề tuổi với sự phát triển kỹ năng của trẻ em. Tuổi, bản thân nó không quyết định sự phát triển (Ormrod, 1995). Không phải tất cả các nhà giáo dục đều hoàn toàn đồng ý với khả năng ứng dụng của các lý thuyết của Piaget vào lớp học. Một trong các nguyên lý được chấp nhận và dựa trên các giai đoạn của Piaget là nguyên lý cần thiết sử dụng các ví dụ cụ thể. Tương tự với nhu cầu khơi dậy các kiến thức, kinh nghiệm có trước của nguời học khi dạy các khái niệm trừu tượng cho trẻ em có thể chưa đạt được giai đoạn các thao tác chính thức. Bản thân Piaget cũng nhận thấy sự thiếu hứng thú khi ứng dụng kết quả của công trình nghiên cứu của mình và ông cũng thừa nhận rằng học có thể thực hiện không cần dạy chính thức vì rằng học chính là sản phẩm của đứa trẻ với môi trường của chúng.
Vận dụng lý thuyết kiến tạo để xây dụng các hoạt động dạy và học

Phương pháp dạy và học theo lý thuyết kiến tạo nhấn mạnh phát triển kiến thức, kỹ năng dựa trên hai hoạt động cơ bản là đồng hóa và điều chinh. Quá trình xây dựng, kiến tạo kiến thức mới là quá trình, hoặc đồng hóa hoặc điều chỉnh giữa kiến thức có trước với kiến thức mới. Mối liên hệ này rất quan trọng và cũng nói nên kiến thức có trước quan trọng đến mức nào trong trong quá trình kiến tạo và hình thành kiến thức mới. Đúng như Tardif (1992) đã nhấn mạnh rằng chúng ta chỉ có thể học được cái mà chúng ta đã biết. Cách tiếp cận theo thuyết kiến tạo giúp người học tổ chức, phân tích, dự báo, giải quyết vấn đề và suy nghĩ lại về những gì họ học được và đặc biệt là quá trình tiếp thu, lĩnh hội nó. Giáo viên có thể giúp đỡ người học bằng cách dạy cho họ những kỹ năng tư duy phù hợp với trình độ phát triển của họ, để họ có thể đi từ những kiến thức và những kỹ năng đã biết tới những kiến thức và kỹ năng chưa biết. Tư duy kiến tạo sẽ giúp tập trung vào việc học tập sâu và tổ chức chặt chẽ các cấu trúc kiến thức được sắp xếp theo một thứ bậc rất rõ ràng. Nó cũng giúp người học đưa ra các quyết định dựa trên việc tìm hiểu các nguồn dữ liệu, cũng như hỗ trợ họ trong việc đánh giá các ý tưởng hoặc giả thiết và tiến hành giải quyết sáng tạo một vấn đề nào đó.

Phương pháp dạy và học theo lý thuyết kiến tạo có một số đặc tính quan trọng sau đây:

- Người học phải sẽ kiến tạo hiệu quả kiến thức nếu dựa trên các kiến thức mà mình đã thụ đắc và lĩnh hội trước đó.

- Người học sẽ kiến tạo hiệu quả kiến thức nếu dựa trên trải nghiệm cá nhân.

- Người học sẽ kiến tạo hiệu quả kiến thức nếu các kiến thức được cấu trúc chặt chẽ.

Kiến thức và kinh nghiệm có trước của người học phải được xem xét và tính đến khi xây dựng bài giảng và khi giảng bài.

Về phương pháp sư phạm, theo Doolittle (1999), có 9 điều kiện cần thiết để thành công một phương pháp sư phạm kiến tạo: 
- Giới thiệu cho người học các tình huống học phức tạp tương tự với các tình huống mà họ gặp trong cuộc sống hàng ngày.

- Tạo thuận lợi cho tương tác và cộng tác giữa những người học.

- Cho người học thấy được ý nghĩa của việc học.

- Bất cứ việc học nào cũng phải xuất phát từ kiến thức có trước của người học.

- Người học phải được đánh giá quá trình liên tục.

- Người học phải chịu trách nhiệm về việc học của mình.

- Người dạy phải là người hướng dẫn, người làm cho việc học dễ dàng.

- Xem lại nội dung và giới thiệu chúng theo các viễn cảnh khác nhau.

Theo lý thuyết kiến tạo, dạy là cung cấp các tình huống trở ngại, khó khăn cho phép thiết lập các biểu đạt thích hợp về thế giới; học là kiến tạo và tổ chức các kiến thức của mình bằng chính hoạt động của riêng mình; và phuơng pháp sur phạm thích hợp là học thông qua giải quyết các vấn đề mở và nghiên cứu trường hợp.

\section{Lý thuyết kiến tạo xã hội}

Lý thuyết kiến tạo xã hội (socioconstructivisme) là một lý thuyết học dựa trên các công trình nghiên cứu của Bandura (1986), đặc biệt là mô hình học xã hội, và được phát triển bởi các nhà tâm lý học xã hội và tâm lý học phát triển xã hội. Như tên của lý thuyết, lý thuyết kiến tạo xã hội có mối quan hệ đặc biệt với lý thuyết kiến tạo. Thật vậy, xuất phát từ lý thuyết kiến tạo, lý thuyết kiến tạo xã hội đưa thêm khái niệm tương tác xã hội, có nghĩa là người học tương tác với những người khác để kiến tạo kiến thức của mình. Bằng việc đưa ra cách tiếp cận tâm lý-xã hội các hoạt động nhận thức, lý thuyết kiến tạo xã hội đặt vấn đề xem xét lại một số nguyên lý của lý thuyết kiến tạo về việc tập trung vào các cơ chế cá nhân, và cập nhật một số đường hướng lý thuyết nhấn mạnh các phương diện xã hội trong hình thành các năng lực.

Theo lý thuyết kiến tạo xã hội, kiến tạo kiến thức, dù rằng mang tính cá nhân, nhưng được thực hiện trong một khung cảnh xã hội. Lý thuyết kiến tạo xã hội là một mô hình dạy và học. Đối với mô hình này, có ba yếu tố phương pháp dạy học, liên kết chặt chẽ với nhau, cho phép sự tiến bộ của người học:

- Phương diện kiến tạo là muốn nói đến chủ thể học: người học.

- Phương diện xã hội là muốn nói đến các đối tác liên quan: những người học khác và người dạy.

- Phương diện tương tác là muốn nói đến môi trường: các tình huống, đối tượng học được tổ chức trong các tình huống này. Đối tượng học được đưa ra là nội dung dạy.

Xuất phát từ lý thuyết kiến tạo, lý thuyết kiến tạo xã hội lấy lại phần lớn lý thuyết kiến tạo hay phát sinh nhận thức (théorie $d u$ connaître) và nhấn mạnh tầm quan trọng của các tương tác xã hội. Thật vậy, cũng nhu lý thuyết kiến tạo, lý thuyết kiến tạo xã hội khẳng định rằng kiến thức là sản phẩm của quá trình kiến tạo. Tuy nhiên, kiến tạo ở đây là kiến tạo mang tính xã hội mà không phải mang tính cá nhân. Theo lý thuyết kiến tạo xã hội, người lớn kiến tạo kiến thức trong các tình huống và trong các ngữ cảnh xã hội mà các tình huống và ngữ cảnh này ảnh hưởng đến việc kiến tạo của người học. Chính vì vậy, kiến tạo một kiến thức, dù mang tính cá nhân, phải thực hiện trong khung cảnh xã hội. Các thông tin có quan hệ chặt chẽ với môi trường xã hội và ngữ cảnh và đến từ cái mà người ta nghĩ và những cái khác mà những người khác mang tới như là các tương tác. Vigotsky 
là người đầu tiên nhấn mạnh tầm quan trọng của yếu tố xã hội trong việc phát triển kiến thức ở trẻ em. Trong một thời gian dài, các công trình nghiên cứu của nhà tâm lý học Nga Lev Vigotsky ngày càng có những ảnh hưởng tới việc phát triển các lý thuyết và thực hành giáo dục ở một số nước, kể cả Bắc Mỹ. Tuy nhiên, theo Davydov (1995), công trình lý thuyết cơ sở của Vygosky "Pedagogycal Psychology" có thể được viết vào năm 1926, nhưng đã không được xuất bản trước năm 1991. Vygotsky (1985) cho rằng sự phát triển nhận thức gắn liền và dựa trực tiếp vào sự phát triển xã hội. Đối với Vygotsky, cái mà đứa trẻ học và cách tư duy của nó chịu ảnh hưởng trực tiếp của tri thức đến từ môi trường xung quanh. Theo ông, trẻ em bắt đầu học từ những từ xung quanh chúng, từ những từ ngữ của xã hội xung quanh từ ngữ hàng ngày là nguồn gốc của tất cả những khái niệm, những ý nghĩ, kỹ năng, thái độ của chúng. Quá trình tâm lý của chúng ta được xây dựng cũng giống như một quá trình xã hội, có nghĩa là nó được đào luyện bằng chính văn hoá của chúng ta. Một người lớn nhận thức các sự vật hiện tượng khác với một đứa trẻ, nhưng sự khác nhau này sẽ giảm dần khi mà đứa trẻ biến đổi tăng dần các nhận thức xã hội thành các nhận thức cá nhân và tâm lý.

Vygotsky luôn luôn bảo vệ quan điểm của ông là không thể có phát triển nhận thức mà không có học. Nói một cách khác, người ta chỉ có thể phát triển nhận thức thông qua học. Hơn thế nữa, hầu hết các công trình nghiên cứu của ông có liên quan đến vai trò quan trọng của các tương tác xã hội trong phát triển nhận thức. Ông cũng khẳng định rằng các tương tác xã hội đóng vai trò hàng đầu trong việc học và ngôn ngữ là công cụ lĩnh hội.

Để bảo vệ các quan điểm của mình, Vygotsky đưa ra khái niệm "vùng phát triển gần" (zone proximale de développement). Đây là khái niệm trung tâm của các công trình nghiên cứu của Vygotsky (1985). Khái niệm này đề cập tới sự khác nhau giữa cái mà đứa trẻ sẽ học nếu học một mình và cái mà đứa trẻ có thể học một cách tiềm năng nếu như đứa trẻ được người khác giúp đỡ.

Do đó, vùng phát triển gần $(\mathrm{ZPD})$ này chính là khoảng cách hay sự khác nhau giữa trình độ phát triển hiện tại được xác định bởi các khả năng của đứa trẻ giải quyết vấn đề một mình và trình độ phát triển tiềm năng được xác định qua việc giải quyết vấn đề của đứa trẻ này, khi mà nó được những người lớn giúp đỡ hay hợp tác với các bạn có trình độ cao hơn.

Trong lý thuyết được phát triển chủ yếu bởi Vygotsky, vùng phát triển gần trước hết là cái mà người học chỉ có thể thực hiện được với sự giúp đỡ của một người có năng lực hơn. Học được coi như là kết quả của các hoạt động nhận thức xã hội gắn liền với các trao đổi sư phạm giữa người dạy-người học và giữa người học-người học. Khái niệm kiến tạo tri thức là sự tiếp tục tự kiến tạo xã hội (autosocioconstruction) các kiến thức bởi những người học.

Những điều kiện đưa người học vào hoạt động là không thể thiếu được trong khuôn khổ kiến tạo hóa xã hội, bởi vì tiếp thu các kiến thức mới và sự hạn chế các kiến thức có trước không phải là các mục tiêu duy nhất của việc học. Học cũng coi trọng sự phát triển khả năng học, khả năng hiểu, khả năng phân tích và việc làm chủ các công cụ học. Cần phải nhấn mạnh rằng quá trình học không còn là quá trình mà ở đó người dạy truyền đạt kiến thức và đưa người học vào hoạt động mà quá trình học còn là việc đưa vào hoạt động tương tác giữa các người học và giữa người dạy và người học. Lý thuyết kiến tạo xã hội đòi hỏi người dạy cũng như người học thoát ra khỏi phân vai truyền thống của mình và người này phải cộng tác với người kia. Ví dụ, thay vì người dạy truyền đạt kiến thức cho người học thì người dạy phải cộng tác với người học 
bằng cách nào đó để người học có thể tự kiến tạo các kiến thức của mình. Người dạy phải đặt người học vào trung tâm suy nghĩ và hoạt động của mình và tạo thuận lợi cho các tình huống tương tác. Khi nhiệm vụ hoàn thành, người ta có thể đánh giá người học đã kiến tạo được một kỹ năng hay kiến thức của riêng anh ta. Sự kiến tạo này trước hết là kết quả của hoạt động và đầu tư của người học trong các tình huống, nhưng cũng chính là nhờ vào các quan hệ của mình với môi trường xã hội, môi trường cho phép người học tự kiến tạo kiến thức.

Nhận xét về lý thuyết kiến tạo xã hội, Ormrod (1995: 59) khẳng định rằng "người dạy tạo điều kiện thuận lợi cho sư phát triển nhận thức của trẻ em bằng cách giới thiệu các hoạt động trên lớp mà chúng chỉ có thể hoàn thành bằng cách nhận được một sụ hỗ trợ - có nghĩa là - ở trong chính mỗi môt vùng phát triển gần của người học." Đối với Gage và Berliner (1988), những vấn đề xuất hiện khi người dạy cho phép người học làm việc một mình quá nhiều và như vậy sẽ làm giảm khả năng phát triển trí tuệ của trẻ. Theo Gage et Berliner (1988 : 126), "sụ làm chủ các cấp độ phức tạp hơn của hoạt động nhận thức có thể diễn ra với sụ hỗ trợ của người lón [...] Chính là con người có hiểu biết hơn sẽ cung cấp một giàn giáo làm nền tảng để đưa trẻ kiến tạo kiến thức mới. Trong vùng phát triển gần này, kiến thức xã hộ-kiến thức thu nhận được qua giao tiếp xã hộ - trở thành tri thức cá nhân và tri thức cá nhân phát triển ở cấp độ cao hơ".

Davydov (1995: 13) tìm ra 5 hệ quả giáo dục cơ sở theo quan điểm của Vygosky:

- Giáo dục có chức năng phát triển nhân cách của trẻ em.

- Nhân cách con người gắn liền với tiềm năng sáng tạo và giáo dục phải được xây dựng để cho phép khám phá, phát hiện và phát triển tiềm năng này ở mức tối đa ở mỗi một cá nhân.
- Dạy và học cho rằng người học khai thác các giá trị bên trong của họ qua các hoạt động cá nhân.

- Người dạy chỉ đạo và hướng dẫn các họat động cá nhân của người học, nhưng không áp đặt và cũng không ép buộc.

- Các phương pháp có giá trị nhất cho việc học của người học là các phương pháp phù hợp với nhu cầu và với các giai đoạn phát triển cá nhân của họ, và như vậy các phương pháp này không thể giống nhau đối với tất cả mọi người học.

Theo lý thuyết kiến tạo xã hội, dạy đó là tổ chức các tình huống học thuận lợi cho đối thoại, trao đổi để tạo nên và giải quyết các xung đột nhận thức xã hội (conflits sociocongnitifs); học là cộng tác với người khác kiến tạo kiến thức của mình bằng cách đối chất các biểu đạt của mình với các biểu đạt của người khác; và phưong pháp sur phạm thích hợp là học thông qua làm dự án, tranh luận, bài tập và nghiên cứu.

Lý thuyết kiến tạo xã hội quan niệm dạy học dựa trên kinh nghiệm cá nhân của trẻ em, đánh giá nhu cầu học qua hợp tác và các hoạt động xã hội, dường như thực sự phù hợp với các quan điểm bước đầu của lý thuyết kiến tạo xã hội.

\section{Kết luận}

Lý thuyết kiến tạo và lý thuyết kiến tạo xã hội ra đời cách đây nhiều thập kỷ, nhưng những giá trị khoa học của hai lý thuyết nhận thức này cho đến nay vẫn còn nguyên giá trị. Lý thuyết kiến tạo đã chứng minh một cách thuyết phục quá trình phát triển nhận thức của con người từ lúc sơ sinh cho đến khi phát triển: kiến thức được kiến tạo trong hoạt động và thông qua hành động bằng hai quá trình đồng hóa và điều chỉnh. Phát triển từ lý thuyết kiến tạo, lý thuyết kiến tạo xã hội một lần nữa khẳng định quá trình phát triển kiến thức là quá trình kiến tạo, nhưng kiến tạo này được 
thực hiện trong các tương tác xã hội. Có thể khẳng định rằng hai lý thuyết kiến tạo và lý thuyết kiến tạo xã hội, cùng với các lý thuyết khác, đã và đang đóng góp to lớn trong giáo dục nói chung và giáo dục ngoại ngữ nói riêng. Những đóng góp này cho phép tạo ra những thay đổi quan trọng trong dạy và học ngoại ngữ.

\section{Tài liệu tham khảo}

\section{Tiếng Anh}

Bandura, A. (1986). Social Foundations of Thought and Action: A Social-Cognitive Theory, Englewood Cliffs, NJ: Prentice-Hall.

Davydov, V.V. (1995). The Influence of L.S. Vygotsky on Education. Theory, Research, and Practice. Educational Researcher. Vol. 24, no. 3, 12-21.

Doolittle, P.-E. (1999). Constructivism and Online Education. http://edpsychserver.ed.vt.edu/ workshops/ tohe1999/online.html
Gage, N. L., \& Berliner, D. C. (1988). Educational Psychology (4th ed.). Boston, MA: Houghton Mifflin.

Ormrod, J.-E. (1995). Human Learning (2nd ed.). Englewood Cliffs. NJ: Prentice Hall.

Piaget, J. (1975). The Origin of the Idea of Chance in Children. London: Routledge and Kegan Paul Ltd.

Selinker, L (1972). Interlanguage. International Review of Applied Linguistics. 10: 209-241.

\section{Tiếng Pháp}

Bruner, J. (1996). L'éducation, entrée dans la culture: les problèmes de l'école à la lumière de la psychologie culturelle. Paris: Éditions Retz.

Piaget, J. (1977). Mes idées, Paris, Denoël/Gonthier.

Tardif, J. (1992). Pour un enseignement stratégique. L'apport de la psychologie cognitive. Montréal, Québec : Logiques.

Vygotsky, L.-S. (1985). Pensée et Langage. Coll. Terrains. Paris : Editions Sociales.

\title{
FROM CONSTRUCTIVISM TO SOCIO-CONSTRUCTIVISM
}

\author{
Nguyen Quang Thuan \\ Center of Linguistics and International Studies, VNU University of Languages and International \\ Studies, Pham Van Dong, Cau Giay, Hanoi, Vietnam
}

\begin{abstract}
Constructivism and socio-constructivism are two important interrelated theories that explain human cognitive development. Constructivism postulates that knowledge is built by action and reflection on action. Like constructivism, socio-constructivism assumes that knowledge is a construction. Nevertheless, this construction would be social rather than individual. This paper attempts to analyze and highlight the important viewpoints of these two theories and their application in language teaching and learning.

Keywords: Constructivism, Socio-constructivism, assimilation, accommodation
\end{abstract}

